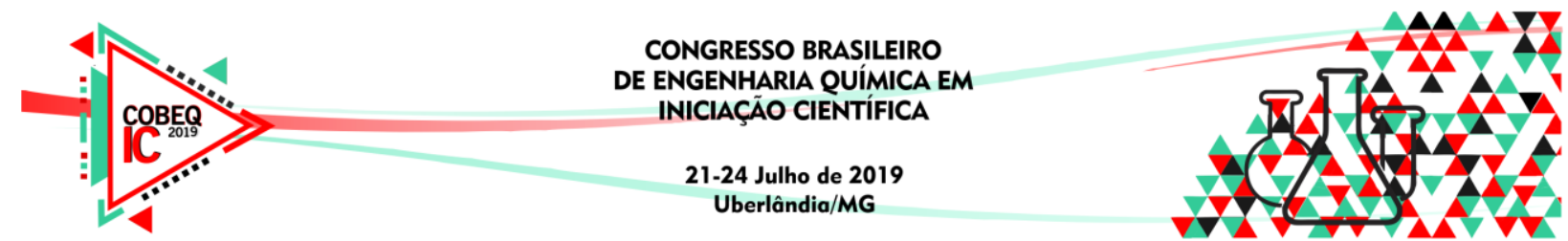

\title{
ANÁLISE DA TEMPERATURA DE CRESCIMENTO DE FUNGOS FILAMENTOSOS PRODUTORES DE AMILASES
}

\author{
I. C. S. AMORIM ${ }^{1}$, J. C. VASCONCELOS ${ }^{1}$, G. O. MARINHO ${ }^{2}$, T. M. F. S. OLIVEIRA. ${ }^{1}$ e \\ V. M. BENASSI ${ }^{1}$ \\ ${ }^{1}$ Universidade Federal dos Vales de Jequitinhonha e Mucuri campus JK, Instituto de Ciência \\ e Tecnologia. \\ ${ }^{2}$ Universidade Federal dos Vales de Jequitinhonha e Mucuri campus JK, Programa de Pós- \\ graduação em Biocombustíveis. \\ E-mail para contato: gessicaomarinho@gmail.com
}

\begin{abstract}
RESUMO - A importância industrial e o alto custo de mercado das amilases exige o estudo em busca de fungos amilolíticos. Por essa razão, o seguinte trabalho objetivou analisar a capacidade de diferentes fungos crescerem em meio Emerson, comparando-o com outro meio rico em amido. Determinou-se a melhor temperatura de crescimento dos fungos isolados de um lixão desativado localizado na Universidade Federal dos Vales do Jequitinhonha e Mucuri campus JK, Diamantina, em diferentes meios de cultivo sólido. Um deles contêm $4 \%(\mathrm{~m} / \mathrm{v}) \mathrm{de}$ aveia Quaker e 2\% (m/v) de ágar e em meio BDA, sendo mantidos por 48 horas nas temperaturas de $30^{\circ} \mathrm{C}, 35^{\circ} \mathrm{C}, 40^{\circ} \mathrm{C}$ e $45^{\circ} \mathrm{C}$. Realizou-se, então, a medição do raio das colônias para determinar a taxa de crescimento em centímetros por hora (cm.h-1). Alguns fungos analisados apresentaram melhor crescimento quando inoculados em meios ricos em amido, caracterizando-se como produtores de amilases.
\end{abstract}

\section{INTRODUÇÃO}

O Brasil é um dos países com maior diversidade de organismos vivos, incluindo os fungos filamentosos que são encontrados em abundância nos distintos habitats (PEREIRA, 2017). A prospecção de fungos filamentos vem se destacando, visto que estes representam uma rica fonte em recursos genéticos para aplicação em inúmeros processos e produtos biotecnológicos (PASIN, 2014).

O uso das enzimas se destaca entre os metabólitos fúngicos explorados. Elas podem ser obtidas dos mais diversos organismos, os vegetais, animais e os microrganismos. Contudo, de acordo com FREITAS et al. (2017), obter enzimas a partir de fungos é um processo menos oneroso e simples. Eles exigem fácil manutenção e excretam as enzimas para o meio externo, como um processo natural que permite aos fungos obter seus nutrientes (SAMSON et al., 2010).

Assim, os microrganismos são tidos como os maiores produtores de enzimas, com destaque para os fungos filamentosos. Eles representam a fonte biológica de enzimas mais significativas perfazendo 60\%, seguida das bactérias e levedura com 4\% (SOARES et al., 


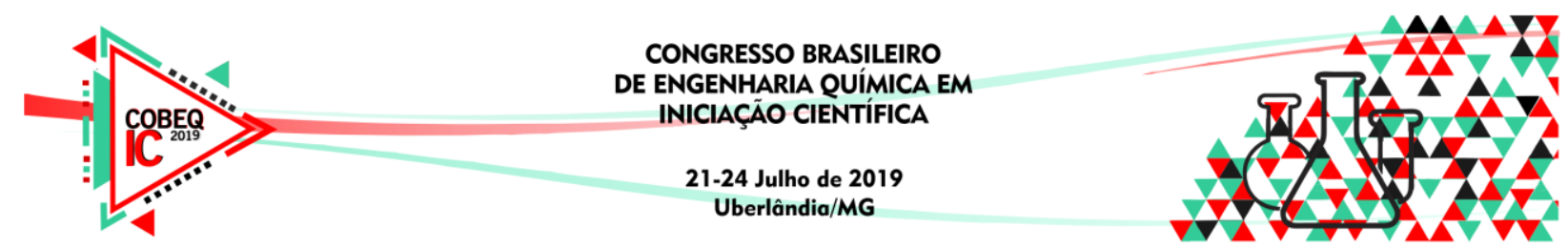

2010; ORLANDELLI, 2012). Utilizar tais organismos para obtenção de enzimas é tido como um processo industrialmente viável, devido ao seu baixo custo (BENNETT., 2010).

A grande diversidade de habitats que esses organismos colonizam, evolutivamente, garantiu a eles grande diversidade metabólica, consequentemente a capacidade de sintetizar uma série de enzimas com diferentes funções. A produção ocorre por meio de um processo simples e facilmente controlado, que os permite serem cultivados em meios de cultura relativamente simples.

As enzimas são catalisadores biológicos, envolvidas na hidrólise de distintas biomassas, pois realizam ações específicas na degradação do substrato de interesse (SILVA et al., 2018). E têm sido usadas como ferramenta para a Biologia Molecular (Taq polimerase), como aditivo de detergentes e sabões (proteases e celulases), no processamento industrial do amido (a-amilase, glucose isomerase) e na indústria de polpa e papel (xilanase) e surgem como alternativas de interesse em outros bioprocessos, como o de síntese orgânica (lipases, proteases, oxidorredutases), no setor de diagnóstico, no tratamento de resíduos e na produção de ração animal.

Das enzimas utilizadas na indústria, aproximadamente $80 \%$ correspondem às hidrolases, entre elas as proteases e amilases lideram a produção mundial em escala industrial, pois são amplamente empregadas na indústria nos mais diferentes setores (BENASSI, 2012). As amilases são enzimas que agem de forma sinérgica na hidrolise das ligações $O$ glicosídicas da molécula do amido, hidrolisando-o em moléculas menores.

Contudo, o seu alto custo de mercado exige o estudo em busca de fungos bons produtores de amilases. Por essa razão, o seguinte trabalho objetivou analisar a capacidade de diferentes fungos crescerem em meio Emerson, comparando-o com coutro meio rico em amido.

\section{METODOLOGIA}

Para analisar o crescimento dos fungos filamentosos selecionados foi utilizado o meio de cultura BDA e meio Emerson (1941). São meios sólidos, onde este último é constituído com $4 \%$ de aveia Quaker® e 2\% de ágar. Para cada isolado procedeu-se o repique pontual em placas de Petri, contendo $10 \mathrm{ml}$ de meio de cultivo, sendo mantidos nas temperaturas de $30^{\circ} \mathrm{C}$, $35^{\circ} \mathrm{C}, 40^{\circ} \mathrm{C}$ e $45^{\circ} \mathrm{C}$. Após 48 horas de cultivo realizou-se a medição do raio das colônias para quantificar a taxa de crescimento das hifas em centímetros por hora (cm.h-1).

Os resultados obtidos foram analisados e os organismos foram classificados de acordo com a sua melhor temperatura de crescimento. Foi determinado $30-35^{\circ} \mathrm{C}$ para fungos mesófilos e acima de $40^{\circ} \mathrm{C}$ para fungos termofílicos (Maheshwari et al., 2000; Oliveira, 2005).

\section{RESULTADOS}

Os fungos em estudos estão depositados em um banco de fungos do Laboratório de Pesquisa em Biocombustíveis da Universidade Federal dos Vales do Jequitinhonha e Mucuri - UFVJM, campus JK, Diamantina, Minas Gerais. Eles são oriundos de diferentes amostras de vegetais em decomposição retirados do lixão dessa mesma cidade. 


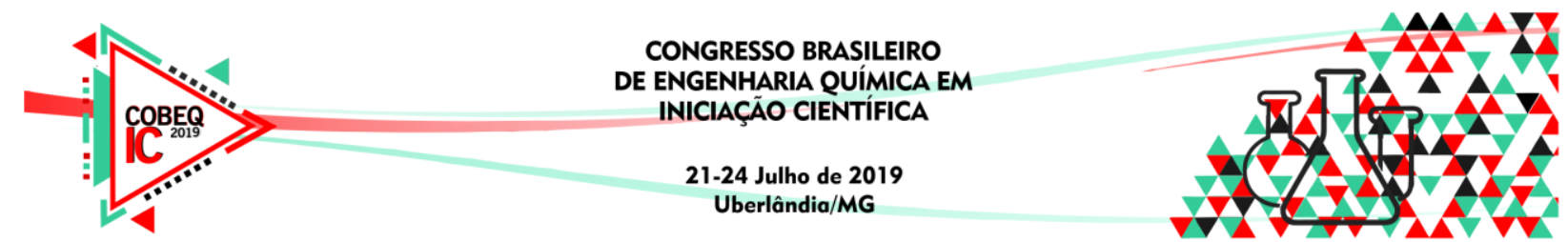

A análise de termofilia permite conhecer a capacidade dos organismos em se desenvolver diante da variação de temperatura e determinar a temperatura ótima de crescimento do organismo. De acordo com essas características, os fungos podem ser classificados em: psicrófilos, quando crescem melhor nas temperaturas de $0^{\circ} \mathrm{C}$ à $15^{\circ} \mathrm{C}$, mesófilos nas temperaturas de $25^{\circ} \mathrm{C}$ à $35^{\circ} \mathrm{C}$ e os termofílicos de $50^{\circ} \mathrm{C}$ à $60^{\circ} \mathrm{C}$ (TORTORA; FUNKE; CASE, 2012).

Observou-se que 11 fungos analisados se desenvolveram melhor á 30C, enquanto 2 fungos apresentaram melhor crescimento à $35^{\circ} \mathrm{C}$. Dessa forma a maioria dos fungos analisados são mesofílicos, ou seja, desenvolveu-se melhor à $30^{\circ} \mathrm{C}$. $\mathrm{O}$ mesmo ocorreu para o desenvolvimento nos dois meios analisados.

Tabela 1- Taxa de crescimento dos fungos filamentosos cultivados em meio Emerson

\begin{tabular}{cccc}
\hline & \multicolumn{3}{c}{ Temperaturas de crescimento } \\
FUNGOS & \multicolumn{3}{c}{$(\mathbf{c m} / \mathbf{h})$} \\
\cline { 2 - 4 } & $\mathbf{3 0}{ }^{\circ} \mathbf{C}$ & $\mathbf{3 5}^{\circ} \mathbf{C}$ & $\mathbf{4 0}^{\circ} \mathbf{C}$ \\
\hline I 1.2 .1 & 0,157 & $\mathbf{0 , 1 7}$ & 0,12 \\
I 2.2 .1 & $\mathbf{0 , 0 5 4}$ & 0,04 & - \\
I 2.2 .3 & 0,17 & $\mathbf{0 , 2}$ & 0.13 \\
I 2.3 .1 & $\mathbf{0 , 0 2 3}$ & - & - \\
I 2.3 .4 & $\mathbf{0 , 0 2 5}$ & - & - \\
I 2.3 .5 & $\mathbf{0 , 0 1 6}$ & - & - \\
I 3.2 .1 & $\mathbf{0 , 5 5}$ & 0,02 & - \\
I 3.2 .2 & $\mathbf{0 , 2 3}$ & - & - \\
I 3.2 .3 & $\mathbf{0 , 0 2 4}$ & - & - \\
I 4.3 .1 & $\mathbf{0 , 0 5}$ & 0,04 & - \\
I 4.3 .2 & $\mathbf{0 , 0 2 3}$ & - & - \\
I 4.4 .1 & $\mathbf{0 , 0 5 8}$ & 0,04 & - \\
I 4.4 .3 & $\mathbf{0 , 0 2 3}$ & - & - \\
\hline
\end{tabular}

Observou-se, também, que alguns fungos como os identificados como I231, I234, I235, I322, I432 e I443 apresentaram crescimento à $35^{\circ} \mathrm{C}$ apenas quando cultivado em meio BDA. Da mesma forma o fungo I441 apresentou crescimento á $40^{\circ} \mathrm{C}$ quando cultivado nesse mesmo meio. Isso pode ser explicado com análise da composição do meio de cultura utilizado.

A produção enzimática dos fungos é um processo natural, que esses organismos utilizam para se nutrirem. Elas são induzidas de acordo com as necessidades que o meio exige, ou seja, de acordo com o nutriente disponibilizado. Então a composição dos meios pode influenciar diretamente. Oliveira et al., (2015), afirma que o potencial enzimático dos 


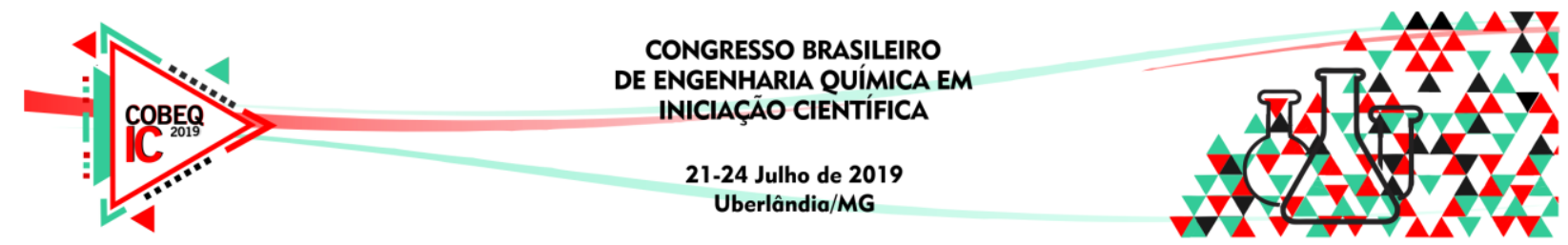

microrganismos está diretamente relacionado com os meios e as condições de temperatura nas quais eles conseguem se desenvolver.

O meio de cultura Emerson, é feito com farinha de aveia, material rico em diferentes nutrientes, o que permite o crescimento de diversos organismo, porém, cada fungo apresenta exigências metabólicas diferentes, podendo ter o seu crescimento ativado ou inibido de acordo com o meio a ele oferecido. Por outra lado, o meio BDA é composto por batata, ou seja, rico em amido. Exige que o fungo produza amilases para se desenvolver nele.

Tabela 2- Taxa de crescimento dos fungos filamentosos cultivados em meio BDA

\begin{tabular}{|c|c|c|c|}
\hline \multirow[t]{2}{*}{ FUNGOS } & \multicolumn{3}{|c|}{$\begin{array}{l}\text { Temperaturas de crescimento } \\
\qquad(\mathrm{cm} / \mathrm{h})\end{array}$} \\
\hline & $30^{\circ} \mathrm{C}$ & $35^{\circ} \mathrm{C}$ & $40^{\circ} \mathrm{C}$ \\
\hline I 1.2 .1 & 0,15 & 0,16 & 0,11 \\
\hline I 2.2 .1 & 0,05 & 0,03 & - \\
\hline I 2.2 .3 & 0,15 & $\mathbf{0 , 1 7}$ & 0,11 \\
\hline I 2.3 .1 & 0,022 & 0,004 & - \\
\hline I 2.3 .4 & 0,016 & 0,004 & - \\
\hline I 2.3 .5 & 0,024 & 0,008 & - \\
\hline I 3.2.1 & $\mathbf{0 , 0 2}$ & 0,018 & - \\
\hline I 3.2 .2 & $\mathbf{0 , 0 2}$ & 0,004 & - \\
\hline I 3.2 .3 & 0,022 & - & - \\
\hline I 4.3.1 & 0,04 & 0,032 & - \\
\hline I 4.3.2 & $\mathbf{0 , 0 2}$ & - & - \\
\hline I 4.4 .1 & 0,056 & 0,037 & 0,005 \\
\hline I 4.4 .3 & $\mathbf{0 , 0 2}$ & 0,005 & - \\
\hline
\end{tabular}

\section{CONCLUSÕES}

Concluiu-se que os fungos analisados cresceram em temperaturas preferenciais de $30^{\circ} \mathrm{C}-35^{\circ} \mathrm{C}$, sendo caracterizados como mesofílicos e poucos organismo apresentaram crescimento à $40^{\circ} \mathrm{C}$. E que alguns fungos apresentaram maior crescimento em meio BDA, mostrando possível potencial amilolítico.

\section{REFERENCIAS}

BENASSI, V. M., et al. Production and action of an Aspergillus phoenicis enzymatic pool using different carbon sources. Brazilian Journal of Food Technology. Campinas, v. 15, n. 3, Set., 2012. 


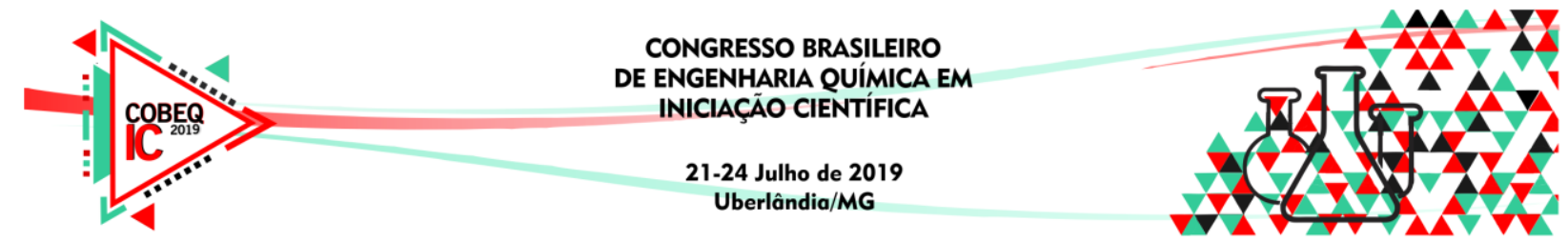

BENNETT, J. W. An overview of the genus Aspergillus. In Masayuki M.; Katsuya G. Aspergillus: molecular biology and genomics (Org.), Japan,p. 1-17, 2010.

EMERSON, R. An experimental study of the life cycles and taxonomy of Allomyces. Lloydia, v. 4, p. 77-144, 1941.

FREITAS, F.; TORRES, C. A.V.; REIS, M. A.M. Engineering aspects of microbial exopolysaccharide production. Bioresource technology, v. 245, p. 1674-1683, 2017.

MAHESHWARI R, BHARADWAJ G, BHAT MK. Thermophilic fungi: their physiology and enzymes. Microbiol Mol Biol Rev 64(3):461-488, 2010.

OLIVEIRA, T. B.; GOMES, E.; RODRIGUES, A.; Thermophilic fungi in the new age of fungal taxonomy. Extremophiles, v. 19, n. 1, p. 31-37, 2015.

ORLANDELLI, R. C. et al. Enzimas de interesse industrial: produção por fungos e aplicações. SaBios-Revista de Saúde e Biologia, v. 7, n. 3, p.97-109, 2012

PASIN, T. M., BENASSI, V. M., MOREIRA, M. A., JORGE, J. A., \& POLIZELI, M. L. T. M. Prospecting Filamentous Fungi for Amylase Production: Standardization of Aspergillus japonicus Culture Conditions. v.4 n.4, p.482-498, 2014.

SILVA, C. F. Isolamento e seleção de micro-organismos produtores de enzimas de interesse comercial. Scientia Plena, v. 14, n. 2, 2018.

SOARES, I. A. et al. Identificação do potencial amilolítico de linhagens mutantes do fungo filamentoso Aspergillus nidulans. Food Science and Technology, Campinas, v. 30, n. 3, p. 700-705, 2010.

TORTORA, GERARD J.; CASE, Christine L.; FUNKE, Berdell R. Microbiologia-12a Edição. Artmed Editora, 2016. 